\title{
Kinematics of Shoulder Injuries in Throwing Sports
}

\author{
Hongqiong Deng ${ }^{1}$, Yuan $\mathrm{Li}^{1}$, Hong Xie ${ }^{1} \&$ Shiwei $\mathrm{Li}^{1}$ \\ ${ }^{1}$ School of Fashion Technology, Shanghai University of Engineering Science, Shanghai, China \\ Correspondence: Liuweimin, Address: School of Fashion Technology, Shanghai University of Engineering Science, \\ Shanghai, 201620, China
}

Received: August 9, 2017

Accepted: October 18, 2017

Online Published: October 22, 2017

doi:10.5430/jbar.v6n2p50

URL: https://doi.org/10.5430/jbar.v6n2p50

\begin{abstract}
Muscle injury mechanism should be studied to know how to prevent the muscle injuries. The purpose of this article is to construct a protecting model of shoulder injuries based on classical mechanism and kinematics in throwing sports like baseball pitching, badminton smash, volleyball smash, javelin throwing process etc, and then introduce the products design. Firstly, the biomechanics of muscle were analyzed based on Newton's classical mechanics; then a finite element analysis was used to simulate the shoulder muscles protection. Protective parameters were got to make the protective clothes; finally, the protective performance and the comfortableness has been evaluated by ten healthy participants with the mean age, height, body mass were 23.5 years (SD, 1.5), 1.75m (SD, 0.07), $60.5 \mathrm{~kg}(\mathrm{SD}$, 9.1), respectively. The throwing test including the baseball pitching, the badminton smash, the process of volleyball smash, and the javelin throwing process. Three protective clothes have been produced and all of them have a protective effect on the muscle while participants were doing the baseball pitching motion, the badminton smashes motion and the volleyball smash. And it has also met the requirement of the human body. But protecting effect each style given was different in different sports motions.
\end{abstract}

Keywords: Biomechanics, Throwing sports, Shoulder injuries, Finite element simulation, Sports protective clothing

\section{Introduction}

Finite element simulation method is used to simulate the knee joint skeletons model (Wang, 2016). The protective parameters were used in the product development and the protective trousers had been developed. With adopting the method of the experimental evaluation to assess the movement performance and the protection, the result showed that the protective parameters did have the protective consequence on the human body and also confirmed that it was feasible to apply the finite element analysis to the sports protective clothing research. Modeling of human muscle tissue photomechanical and the calculating method has been studied (An, 2015). Firstly the anatomical structure of human body muscle tissue and its dynamic characteristics was studied, and the human body muscle tissue was treated as the approximation of nonlinear incompressible super elastomer. The human body muscle tissue biomechanical model was set up. Then based on the theory of continuum mechanics and the method of the finite element, the biomechanics of human muscles model were calculated. Based on image, muscle geometric model was built (Gao, 2014). Muscle tissue density non-uniform distribution model is established based on the theory of finite element method and the energy equation, get muscle stress relationship matrix. A compared finite element model of a normal shoulder and arthritis shoulder has been built (Büchler, Ramaniraka \& Rakotomanana, 2002). CT scans data of skeletal muscle were used to construct the model of the shoulder. The photomechanical properties of rotating condition and the stress distribution under the action of the shoulder blades can be reflected by the shoulder model.

Reverse movement in the upper stage of the muscles around shoulder joint motion sequence is the deltoid muscle hills muscle - muscle under the post - small circular muscle - subscapularis, muscle activity decreases in forward throwing stage, biceps is almost stationary, and with the wave phase due to the muscles to reduce loading ( Jobe, Tibone \& Perry, 1983). By studying the action around shoulder joint muscle electromyography in baseball throwing, the sequence of the muscles around shoulder joint was found: the muscle contraction strength of the upraspinatus, infraspinatus and small circular muscle, deltoid, trapezius, biceps decreased in turn at arm crimping stage. By analyzing the mechanics electromyography, the main function of the pectoral is major, serratus anterior, subscapularis and the latissimus-dorsi is to make the arm to put the ball forward. These muscles had stronger strength in the mid-term (Gowan, Jobe \&Tibone, 1987).

By analyzing the commonly three kinds posture of tennis, Wang found that the IEMG was stronger in the trapezius, 
deltoids and biceps, so appropriate support pressure need to design to the regions to improve the comfortableness of the human body, stimulating muscle movements, and reduce the unnecessary energy loss joints moving (Wang, 2016). But the measure of the pressure was not studied in that research.

\subsection{The Biomechanics Principles of Muscle Based on Newton's Classical Mechanics}

The most authoritative three elements muscle model was constructed by Hill (Nordin \& Frankel, 2001). The mechanical properties of the muscle tendon is like a spring elastic structure, is in series with the composition of muscle contraction CC (elastic in myofibril protein, actin and myosin), and the CC is in parallel with the PEC (muscle, muscle membrane, endomysium and sarcolemma). Muscles, tendons unit expressed by the following diagram (Fig 1).

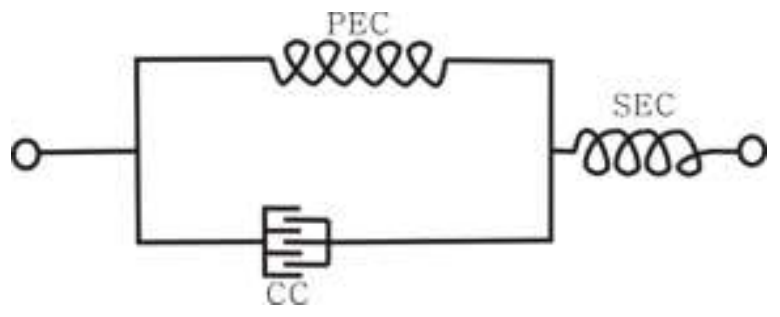

Figure 1. Simplified muscle stretch model

The parallels and series of the elastic elements in the process of muscle contraction and passive pull elongated, produce tension stored elastic potential energy at the same time; the elastic component will retraction when muscle relaxation, the stored energy will be released. The force created by muscles in the process of contract in the attachment of osseous leveraged is called muscle tension. The external force worked on the muscle is called the resistance or load.

Due to the activities of the muscle muscles tendon, but also the shoulder muscle contraction force of the intersection, the local repeated friction, pressure and impact, can make the upper muscle tendon congestion, edema, degeneration, and even fracture, Tendon is highly susceptible to injury (Fritz, Stoller, 1997). Supraspinatus tends to be fatigued and also injured most easily in the process of throwing (Beckett, Hannon \& Ropiak, 2014; Meng, 2015). For example, at the late stage of hand-waving in baseball, humeral head and adhesion of soft tissue are close to the lower surface of shoulder peak, and when imbalance force happens in supraspinatus, there will be friction and collision between the soft tissue and shoulder peak. In the process of lifting, the trigonous muscle and the upper muscle on the co-contraction, the rotator cuff muscle structure will produce a compression force on the humerus, thereby preventing the humeral head subluxation. The extension of the upper limb is primarily performed by the deltoid muscle, the suprachoroid muscle and the subscapular muscle in the process of stretching the upper arm to maintain centrifugal contraction activities, thereby offsetting the force caused by shoulder forward (Inman \& Saunders, 1996). Long-term friction and impact may result in bone hyperplasia in the lower surface of the shoulder peak and shorten the distance with humerus, making it more likely to get injured (Lädermann, Chagué \& Kolo, 2014). This may cause acute muscle injury, because it cannot bear the external load any more.

Therefore, this article mainly analyzes the force between supraspinatus and humerus which effects supraspinatus most. And then find a way to prevent supraspinatus being injured based on the mechanical behavior. Rotator cuff muscle group in the late hand waving stage muscle strength distribution of the diagram below (Fig 2, Fig 3) (Knudson, 2012).

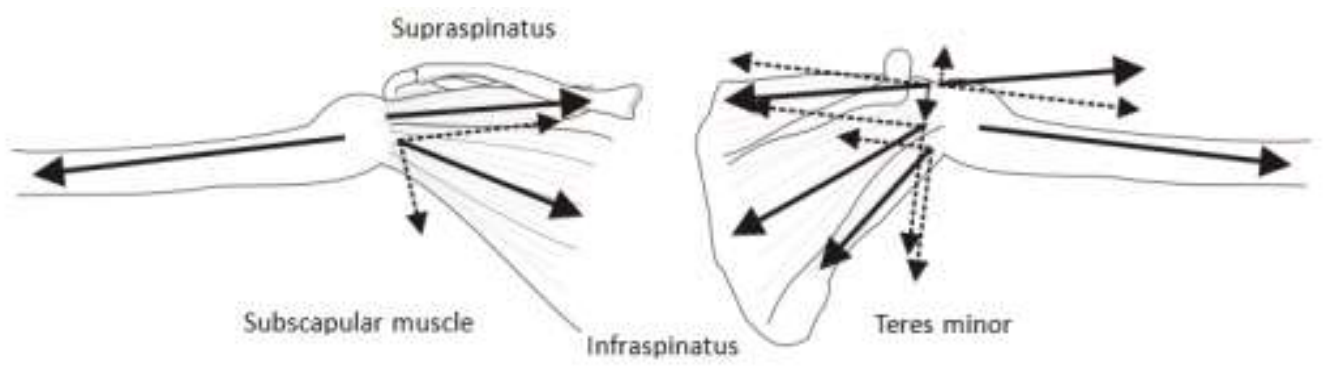

Figure 2. Force diagram of shoulder muscles and humerus at the late stage of cocking 


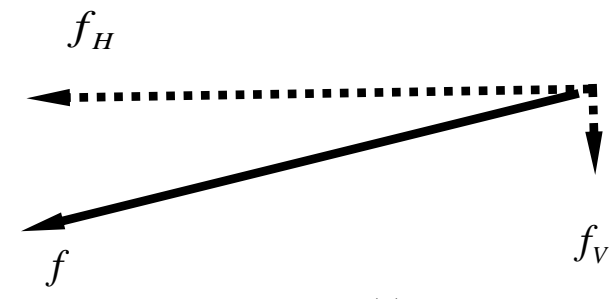

(a)

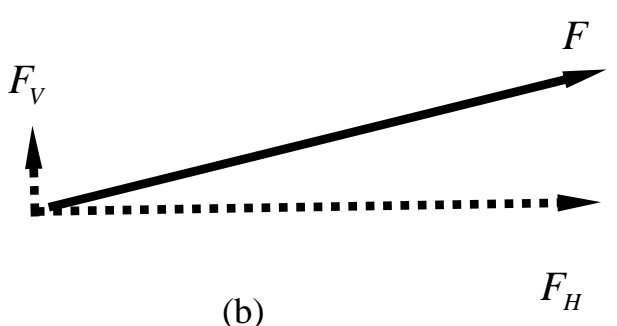

(b)

Figure 3. Resolution of force diagram of humerus

(a) and of the superior muscle (b) at the late stage of cocking

$F$ : resultant force by humerus to supraspinatus;

$f$ : resultant force created by supraspinatus, counterforce of $F$;

$F_{V}$ : component force in vertical direction by humerus to supraspinatus;

$f_{V}$ : component force in vertical direction by supraspinatus to humerus, counterforce of $F_{V}$;

$F_{H}:$ component force in horizontal direction by humerus to supraspinatus;

$f_{H}$ : component forces in horizontal direction by supraspinatus to humerus, counterforce of $F_{H}$.

Force $f$ and $F$ are counterforces to each other. From the resolution of a force diagram, in the late stage of cocking, supraspinatus have squeezing effect on the humerus, similar to the rotator cuff muscles. So, in order to prevent supraspinatus being injured, an external force perpendicular to the humerus can be applied by the protective clothes or a bandage (Fig 4).

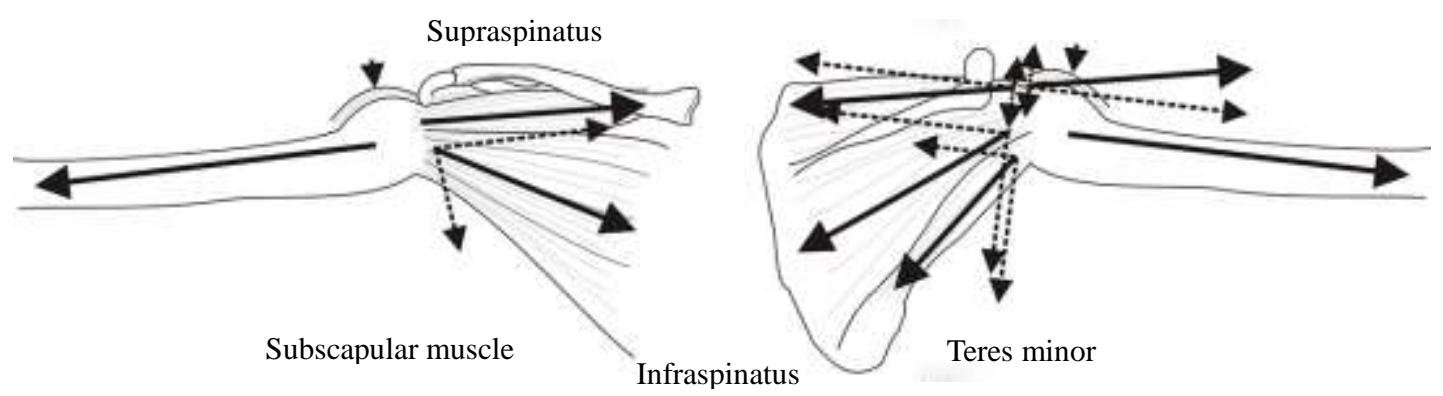

Figure 4. Force diagram of shoulder muscles and humerus under pressure in the late stage of cocking

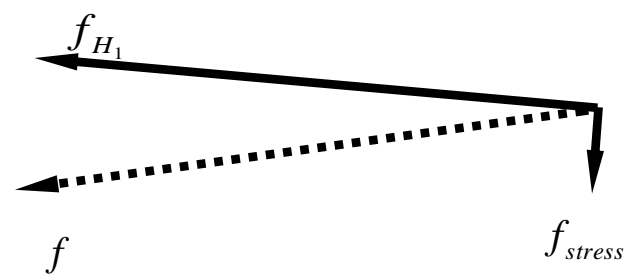

(a)

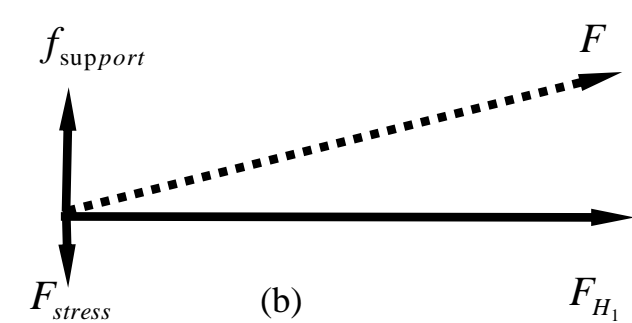

(b)
$F_{H_{1}}$

Figure 5. Resolution of force diagram of humerus (a) and of the superior muscle (b) with external pressure at the late stage of cocking

To avoid sports performance being affected, resultant force $f$ on humerus cannot be changed by adding protected clothes. External stress created by protecting clothes $f_{\text {stress }}$ should be perpendicular to the humerus in a proper size so that $f_{\text {stress }}$ can instead of $f_{V}$ which must be created by supraspinatus but does not change the resultant force $f$ (Fig 5). Thus, resultant force created by supraspinatus can be reduced, which may delay the fatigue of supraspinatus.

In the throwing sports (like the baseball pitcher, javelin throwing smashes, badminton, volleyball spiking) process, 
the forms of the upper arm are identical, they are only different in the range and time of the movement. So throwing sports have the same shoulder injury mechanism. A certain amount of pressure added to the junction between supraspinatus and humerus can play a role to protect the shoulder.Protective clothing for the protection of the body, through the pressure on the shoulder. This article will take the late stage of cocking of baseball as an example.

In order to get the proper stress that protective clothes supplied, considering the maximal force at the critical point may hurt people who participate in the experiment. Stimulative experiment has been conducted as follows to find the optimum stress and its location.

\section{Methodology and Statistic Analyses}

\subsection{Finite Element Analysis to Shoulder Muscles Protection}

From the analysis of the forces shoulder muscles bared in throwing, supraspinatus can be protected by adding a proper component force to reduce the resultant force supraspinatus produced. To carry on this simulation, this section will build a shoulder muscle protecting model by the finite element software ABAQUS. This process has determined appropriate external force application scope by observing the influence external forces have on the muscle tissue and the humerus.

This model is composed of the humerus and the soft tissues around it. This model was built from CT data and mimics16.0 software, after processing and threshold analysis, bone and muscle had clear boundaries. To separate the shoulder blade and humerus from muscle, the bones were colored. And then humerus was found, the size and location of human bones were chosen and measured in mimics16.0 (Fig 6).

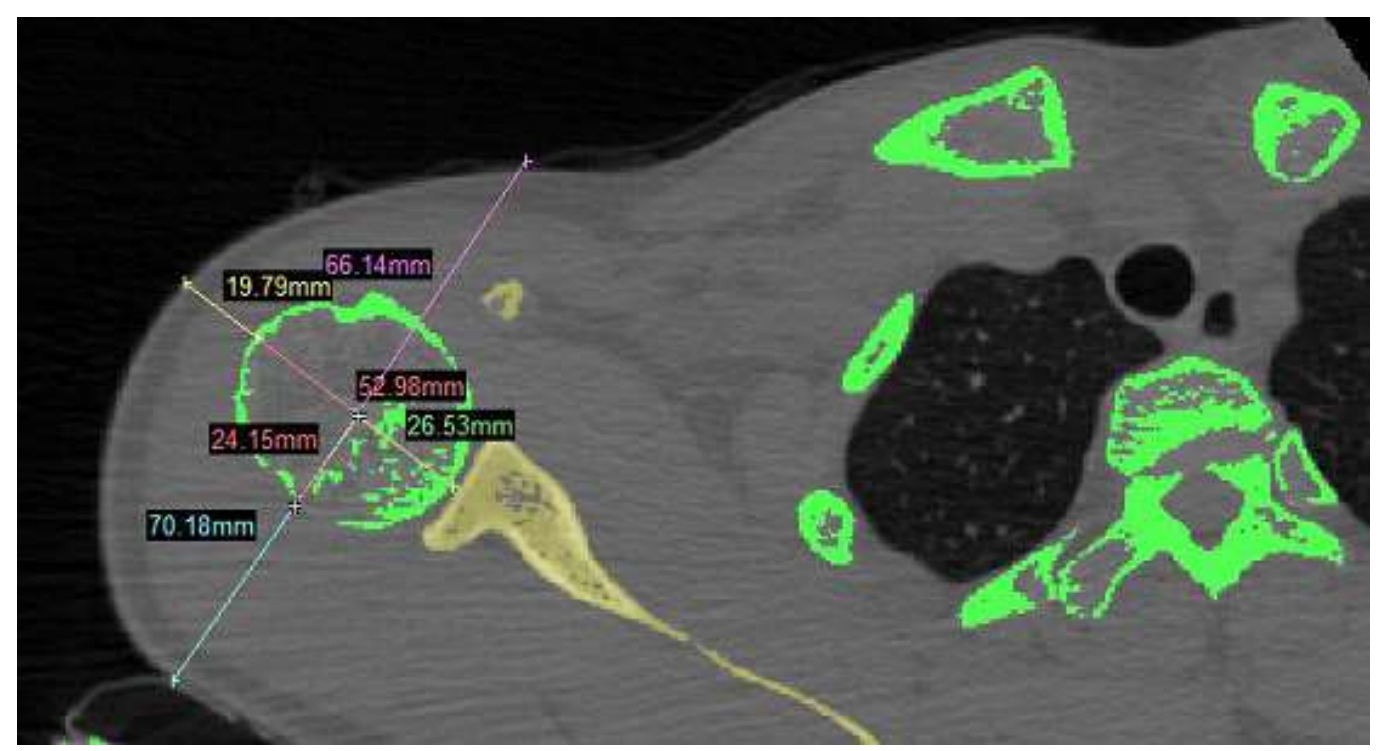

Figure 6. Area of the largest cross section of the humerus in Mimics

Because three-dimensional skeletal muscle images were shown as a complex surface structure in mimics16.0, and its meshing quality could not meet the requirements of dynamic analysis in ABAQUS. The shoulder musculoskeletal model has been simplified. The structure of the muscle in the human body is similar, therefor the muscles around the humerus can be treated as a whole. And the humerus texture is hard but not easy to deformation. It can be treated as a rigid body. In a finite element model an elliptic ring can be used to take the place of humerus, no freedom of the oval ring was wore. It has been constructed in ABAQUS part module according to the measure. Work location was given directly above the junction of the supraspinatus and humerus, covered the entire surface of the transition area. Take muscle tension: muscle elastic modulus is $83 \mathrm{kPa}$. Poisson's ratio of 0.4 , the density is $0.938 \mathrm{~g} / \mathrm{cm} 3$ (Yuan \& Zhang, 2011).

Comfortable clothing pressure is in the range of $1.96-3.92 \mathrm{kPa}$, and it will affect the comfortableness when the garment pressure exceeds 5.88-9.81 kPa (Jian, 2000). So taking $7.85 \mathrm{kPa}$ as the maximum stress value on the surface of the muscle, and the maximum exterior load depends on it.

Loading the model, the range of stress is $3.85-6.85 \mathrm{kPa}$. And the stressed area was discussed in $1 \mathrm{~cm}^{2}$ (the area of $1 \mathrm{~cm} \times 1 \mathrm{~cm}$ square, the other area mentioned later in this article also marked in this way), $4 \mathrm{~cm}^{2}, 9 \mathrm{~cm}^{2}, 16 \mathrm{~cm}^{2}$, and $25 \mathrm{~cm}^{2}$. With $1 \mathrm{~cm}^{2}$ pressure area, from $3.85 \mathrm{kPa}$ to $3.95 \mathrm{kPa}$, the maximum stress value decreased, and then increased 
when the stress increased from $4.85 \mathrm{kPa}$ (Fig 7). And the muscle stress is in a comfortable range when the load is between $3.85 \mathrm{kPa}$ and $3.95 \mathrm{kPa}$, but beyond a comfortable range when the load exceeds $4.85 \mathrm{kPa}$ (Tab 1).

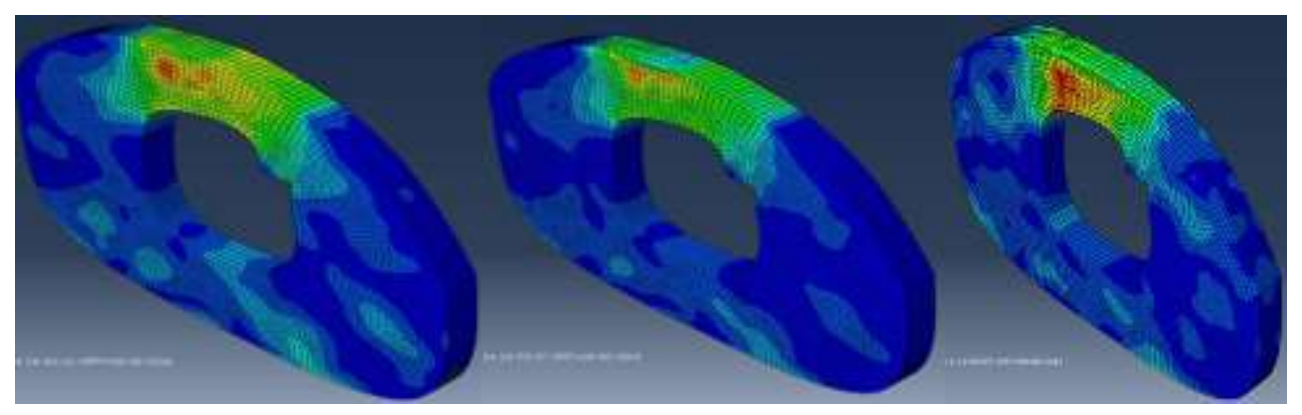
$3.85 \mathrm{kPa}$
$3.95 \mathrm{kPa}$
$4.35 \mathrm{kPa}$

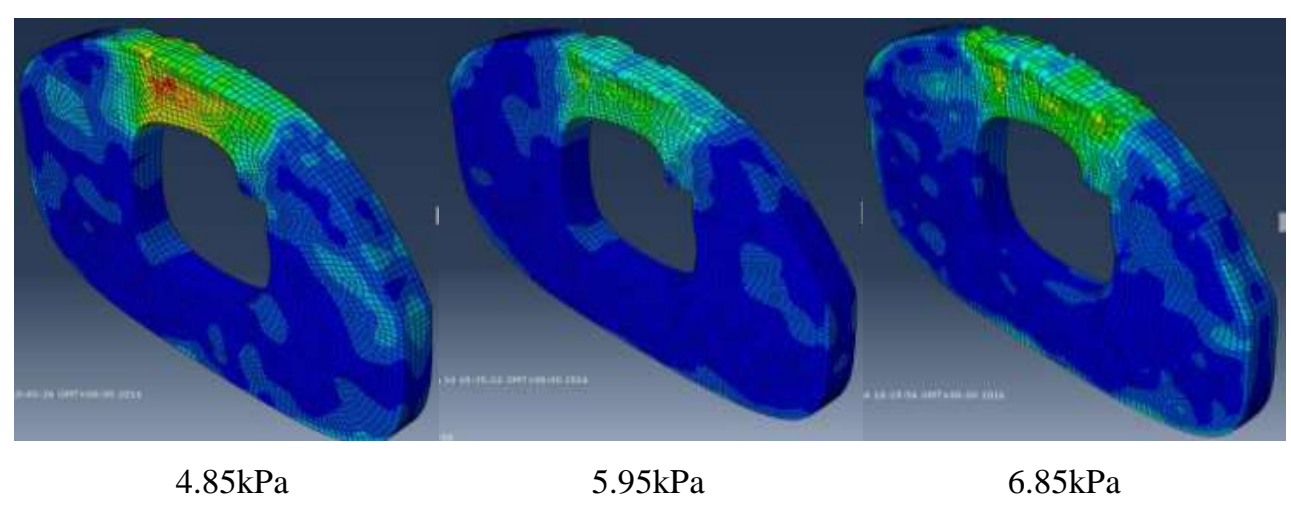

Figure 7. Stress contours of the muscle with no edge in $0.1 \mathrm{~cm}^{2}$ pressure area

Table 1. The table of muscle stress for maximum stress range with no edge muscle model in $0.1 \mathrm{~cm}^{2}$ pressure area

\begin{tabular}{cc}
\hline Stress $/ \mathrm{k} \mathrm{Pa}$ & The highest stress value range/k Pa \\
\hline 6.85 & $17.12-18.67$ \\
5.85 & $15.24-16.60$ \\
4.85 & $8.05-8.77$ \\
4.35 & $6.91-7.53$ \\
3.95 & $6.95-7.57$ \\
3.85 & $5.24-5.71$
\end{tabular}

With $0.1 \mathrm{~cm}^{2}$ pressure area, when the external load is lower than $4.35 \mathrm{k} \mathrm{Pa}$, the maximum stress value range is 5.244 $7.537 \mathrm{k} \mathrm{Pa}$, within the comfortable range. However, in the process of actual protection product design and wearing, protection product scope of the pressure is located parts of human body, which will affect the adjacent muscle around the pressure area. So it is necessary to study the situation of the muscle model with edge. Here is the stress contour of the muscle with no edge in the situation of $0.4 \mathrm{~cm}^{2}$ pressure area (Fig 8 ). 


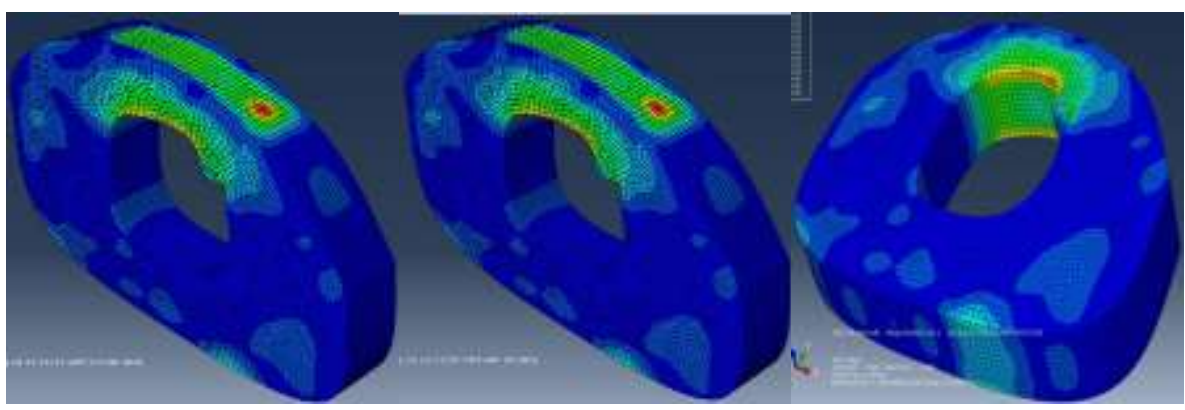

$$
3.92 \mathrm{kPa} \quad 3.94 \mathrm{kPa} \quad 3.94 \mathrm{kPa}
$$

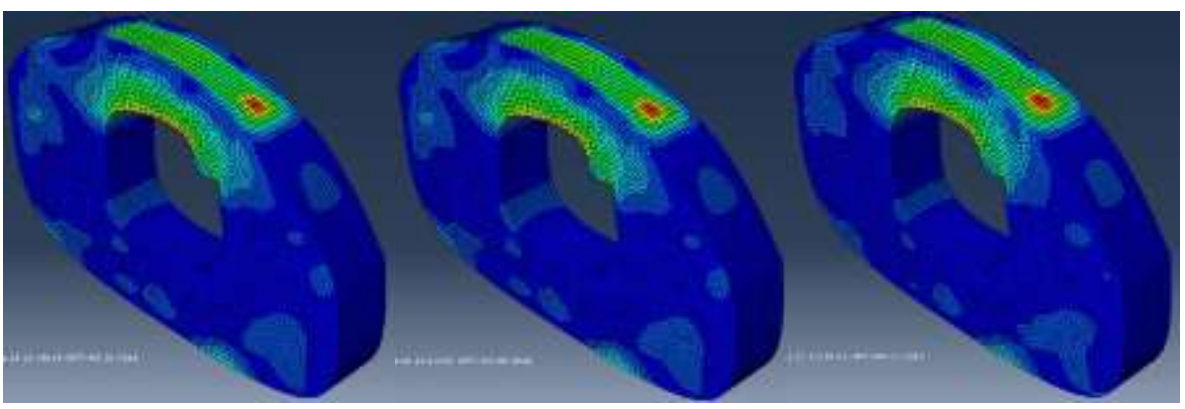

$3.95 \mathrm{kPa}$

$4.05 \mathrm{kPa}$

$4.35 \mathrm{kPa}$

Figure 8 . Stress contours of the muscle with edge in $0.1 \mathrm{~cm}^{2}$ pressure area

There is no severe compression deformation on the surface of the muscle when the pressure is 3.92-3.96 k Pa. The upper and lower limits of the maximum stress increased as the external pressure increased (Tab 2, Fig 8). When the external pressure was more than $3.95 \mathrm{kPa}$, the maximum stress of the muscle reached the upper limits, so it is not suitable. The humerus was simulated by a vacancy humerus shape in the bottom of the area in the shoulder muscles model. The stress distribution is not uniform in the upper surface of the humerus, ranged from $0-7.83 \mathrm{kPa}$. But the stress just below the pressure was in a smaller range of $2.20-3.96 \mathrm{kPa}$, which is different from other parts. This can prove that external pressure can be passed to the humerus by muscles, and part of the stress has been dissipated in the process.

Table 2. The table of muscle stress for maximum stress range with edge muscle model in $1 \mathrm{~cm}^{2}$ pressure area

\begin{tabular}{cc}
\hline Stress $/ \mathrm{k} \mathrm{Pa}$ & The highest stress value range/k Pa \\
\hline 3.92 & $7.16-7.80$ \\
3.94 & $7.18-7.82$ \\
3.95 & $7.19-7.83$ \\
4.05 & $7.20-7.85$ \\
4.35 & $7.22-7.87$ \\
\hline
\end{tabular}

Take the same analysis to other 4 kinds of situations, here are the summary dates (Tab 3). The maximum stress of the muscle increased as the external pressure increased, was positively correlated. When the pressure area is $25 \mathrm{~cm}^{2}$, the maximum stress is less than $7.85 \mathrm{kPa}$ only when the external pressure $3.80 \mathrm{kPa}$, without any pressure range, so it is difficult to get the protective pressure steadily. And when the pressure area is $16 \mathrm{~cm}^{2}$, the external pressure range is nearest to the comfortable clothing pressure requirements. Therefore, consider the protection and wearing comfort, $16 \mathrm{~cm}^{2}$ was selected as the most appropriate protective area. 
Table 3. The table of data summary

\begin{tabular}{ccc}
\hline Pressure area & Stress $/ \mathrm{kPa}$ & The highest stress value range $/ \mathrm{kPa}$ \\
\hline $1 \mathrm{~cm}^{2}$ & 7.22 & $2.20-3.96$ \\
$4 \mathrm{~cm}^{2}$ & 4.69 & $1.99-3.29$ \\
$9 \mathrm{~cm}^{2}$ & 4.07 & $1.98-3.27$ \\
$16 \mathrm{~cm}^{2}$ & 3.94 & $1.99-3.94$
\end{tabular}

\subsection{The Relationship between the Shoulder Protection Area and the EMG}

Surface electromyography (sEMG), which reflects to some extent the underlying intramuscular activity (Nie, 2010), has so far been widely used in the calculation of muscle force (Fridén \& Lieber, 1992) and evaluation of muscle fatigue. The relationship between the IEMG (integral EMG) of the muscles in lower limbs and the average peak torque was in moderate or high positive correlation, which showed that the muscular force can be sufficiently reflected by sEMG $(\mathrm{Li}, 2004)$. Using sEMG is a simple method in exercise physiology and is commonly used to study muscle fatigue, as a non-invasive and quantitative research method, it can study the variation characteristics in the process of local muscle fatigue, to reveal the mechanism of muscle fatigue and judgment in the sports practice fatigue. Methods of electricity (sEMG) signals recorded from skin surface through the electrode lead of anatomical system of electrical activity in the one dimensional time series signal, there exists a good linear relationship between the signal time and frequency characteristics of the signals and the local muscle contraction force and fatigue state, and is often used for technical rationality analysis and project athlete athletics local muscle force situation assessment, taking IEMG as the symbol of the muscular strength. This method has achieved satisfactory results .

This experiment is designed to observe the electrocardiography signal (EMG) on the belly of the supraspinatus under the same external pressure but with different protection area. If the IEMG decreased with lower external force, explains the external forces split the part of the supraspinatus real force. It can indicate that the mean of adding pressure by protective clothes is practicable. The experimental schematic diagram is as follows (Fig 9).

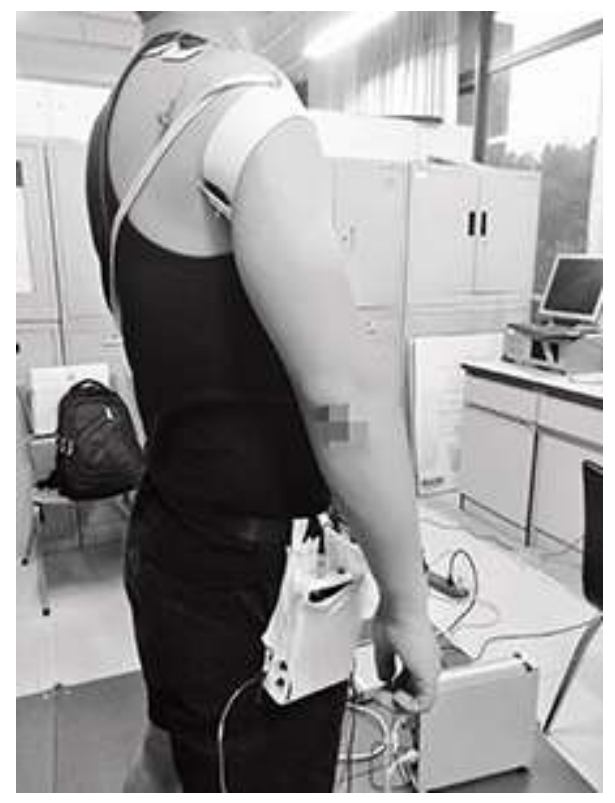

Figure 9. Photograph of experiment

Materials: The Velcro; the electrode patches; elastic rubber belt with a width of $4 \mathrm{~cm}, 3 \mathrm{~cm}, 2 \mathrm{~cm}, 1 \mathrm{~cm}$ and the same length and the same Velcro location distance.

Subjects: 10 healthy young college students participated in this study. None of the participants was injured or in pain. The mean age, height, body mass were 23.5 years (SD, 1.5), 1.75m (SD, 0.07), 60.5kg (SD, 9.1), respectively.

Procedure: All the participants wore vests, shorts and sneakers. No accessories were worn. Put the paste in the same position on the belt, then put the elastic belt on the shoulder. One end of the elastic belt near the shoulder peak 
position $0.5 \mathrm{~cm}$. Patch electrode patches on the belly of supraspinatus, which is the common area of the supraspinatus and trapezius muscle. Participants wore the elastic rubber belt with width of $4 \mathrm{~cm}, 3 \mathrm{~cm}, 2 \mathrm{~cm}, 1 \mathrm{~cm}, 0 \mathrm{~cm}$ (did not wear the belt), respectively, doing throwing sports at the late stage of cocking in baseball. The elasticity with two fixed belt, attached to the same length, should be fixed in the same physical location.The subjects wore up before doing the sport. And doing the throwing motion 5 times per pressure size. Took a rest for a minute during the five times, after finished the five times, took a break for five minutes, took ten minutes each in an elastic belt protection device change. Each time, after finishing the throwing, 250 data was analyzed.

Results: The IEMG decreased as the protective area of supraspinatus and trapezius increased (Tab 4). This is because the external pressure had alleviated the burden of the supraspinatus. When the external pressure increased, the activity of the supraspinatus reduced. Resulting reduced the IEMG of the muscle. Therefore, reasonable pressure on the humerus can effectively reduce the burden of the supraspinatus. And the electromyographic signal can be used for protective performance evaluation in shoulder throwing sports.

Table 4. The recording table for electric signal of muscle with protective state

\begin{tabular}{lll}
\hline Protective area & Interval & IEMG/mv.Frame \\
\hline $0 \mathrm{~cm}^{2}$ & 250 & 1.59 \\
$1 \mathrm{~cm}^{2}$ & 250 & 1.59 \\
$4 \mathrm{~cm}^{2}$ & 250 & 1.58 \\
$9 \mathrm{~cm}^{2}$ & 250 & 1.47 \\
$16 \mathrm{~cm}^{2}$ & 250 & 1.24 \\
\hline
\end{tabular}

\subsection{Design and Evaluation of the Protective Clothes}

The aim of designing the protective clothes is to protect the shoulder by adding pressure on the junction of humerus and supraspinatus. The direction of pressure is perpendicular to the junction. It has been demonstrated that $16 \mathrm{~cm}^{2}$ is the most proper protective area in the contest by building the finite element simulation shoulder model and the electrical experiment. Since the surface of the shoulder is curved, the location of the protective product tied it will shift easily, this will effect the needed pressure, so taking the appropriate fixed way is the most important part of product design. The protective function and comfort of the clothes should be both considered. In order to balance both of them, three fitting contrast designs of the protective clothing have been made to find the bandaging method (Fig 10).

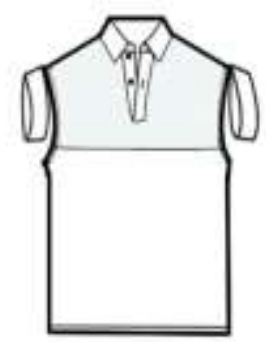

Style $1(\mathrm{~F})$

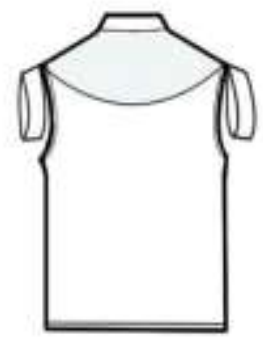

Style 1 (B)

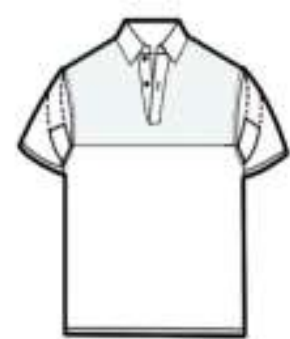

Style $2(\mathrm{~F})$

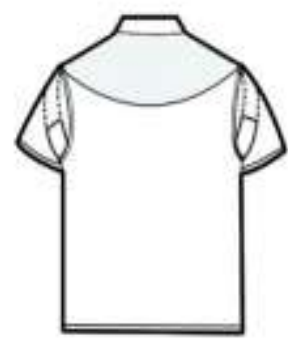

Style 2 (B)

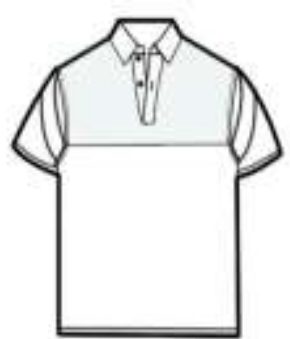

Style 3 (F)

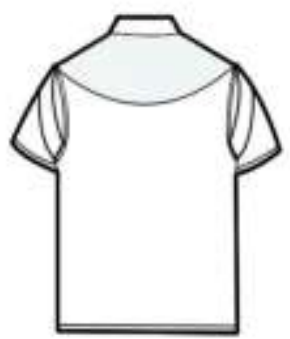

Style 3 (B)

Figure 10. Apparel format drawing of protective clothing

The structure line in the front and back of the protective clothing is $4 \mathrm{~cm}$ above the bust line. Woven fabric made of $65 \%$ polyester and $35 \%$ cotton was used in the patterns above the structure line. And knitted fabric made of $95 \%$ 
modal and 5\% spandex with two ways to stretch was used in the patterns under the structure line. The application of this kind of elastic fabric is for the comfortableness, and the woven fabric is for the stress and stability. Elastic band is made of eight latex silks elastic yarn with Velcro both ends adopted in shoulder, sewn in the shoulder point of the pattern, making it located in the border of the humerus and supraspinatus stably. Cardigan design is to make it easy to slip off and on, and also button up the front fly can keep the elastic band stable.

\subsection{Function Evaluation}

Due to the fabrics upper and down the protective clothing were different, elastic performance in the structure line depends on the knitted fabrics, made arm stuck at armhole easily, and limited the activities at the withers. So, the structure line in the back should be adjusted higher to shoulder to provide more space for the shoulder blades activities, fabric distribution remains the same. The three styles have differences only in sleeves: style 1 is sleeveless; for style 2, the elastic band across the sleeves with Velcro in the armpits; for style 3. The elastic band is outer around the whole sleeves. They were all wore in the ten participants who conducted the EMG experiment in the contest above tried the garments. In the process of wear, the three styles were all easy to slip off and on and the position of the protective bands was stable.

The subjects wear protective clothing (Style 1, Style 2 and Style 3) as the protective group, a sports vest for unprotected experimental group. The Velcro adjustment to the same location where the subjects felt comfortable. The protective performances were evaluated by IEMG. The throwing test including the baseball pitching, the badminton smashes, the process of volleyball smash, and the javelin throwing process. Compared to the unprotected, the IEMG of subjects who wore protective clothes is smaller. As for the comfortableness, Style 2 and Style 3 is better than Style 1. But in the javelin, it has the contrary result ( $\mathrm{Tab} 5$ ).

Table 5. Protection performance test table of protective clothing under the same compactness

\begin{tabular}{lllll}
\hline Sports types & Protection state & Interval & IEMG/mv.frames & Comfortableness \\
\hline \multirow{3}{*}{ Baseball } & No protection & 211 & 2.75 & Comfortable \\
& Style 1 & 211 & 2.38 & Uncomfortable \\
& Style 2 & 211 & 2.58 & Less comfortable \\
& Style 3 & 211 & 2.25 & Less comfortable \\
\multirow{3}{*}{ Badminton } & No protection & 181 & 2.24 & Comfortable \\
& Style 1 & 181 & 2.03 & Uncomfortable \\
& Style 2 & 181 & 2.03 & Less comfortable \\
& Style 3 & 181 & 1.75 & Less comfortable \\
Volleyball & No protection & 136 & 2.72 & Comfortable \\
& Style 1 & 136 & 1.92 & Uncomfortable \\
& Style 2 & 136 & 2.39 & Less comfortable \\
& Style 3 & 136 & 2.35 & Less comfortable \\
& No protection & 201 & 2.15 & Comfortable \\
Javelin & Style 1 & 201 & 2.48 & Uncomfortable \\
& Style 2 & 201 & 2.26 & Less comfortable \\
& Style 3 & 201 & 2.30 & Less comfortable
\end{tabular}

Three kinds of protective clothes all have protecting effect on the muscle while participants doing the baseball pitching motion. The badminton smashes motion and the volleyball smash. But protecting effect each style given was different in different sports motions. So in order to choose the most effective protection, the IEMG was compared in each kind of sport by wearing the three styles (Tab 6). The data include two aspects: one is the difference between the two numbers which were got when subjects in protective or unprotected clothing; the other is the percentage ratio of the difference of the IEMG of protected conditions for unprotected conditions. 
Table 6. Analysis table of protective effect under the same compactness

\begin{tabular}{lllllll}
\hline Difference in IEMG & & \multicolumn{5}{c}{$\begin{array}{l}\text { Difference in } \\
\text { conditions/\% }\end{array}$} \\
\hline & Baseball & Badminton & Volleyball & Baseball & Badminton & Volleyball \\
Style 1 & 0.37 & 0.21 & 0.79 & 13.46 & 9.45 & 29.29 \\
Style 2 & 0.16 & 0.21 & 0.32 & 5.97 & 9.41 & 12.01 \\
Style 3 & 0.50 & 0.49 & 0.37 & 18.20 & 21.99 & 13.59
\end{tabular}

Under the same external pressure, the protective effects of the three styles are Style 3>Style 1>Style 2 in baseball pitching and badminton smashes; Style 1>Style 3>Style 2 in volleyball smash. As for the comfortableness, Style 3>Style 2>Style 1. Discomfort mainly comes from the under arm. Sleeveless Style L1, contacted with the human body directly, with a narrow stressed area, and the muscles under the arm are relatively underdeveloped, so this caused skin sag inward while external pressure put on the area. Style 2 and Style 3 are both have sleeves, the protective device contact skin across from sleeves, so the stressed area is bigger, pressure on the muscle is relatively small, so the body feels more comfortable. Using the five scale scores to express the subjective feeling, the corresponding scale of each level is as follows (Tab 7).

Table 7. The five subjective feeling scale scores

\begin{tabular}{lllll}
\hline Subjective feeling & Best & Good & Less good & Poorest \\
\hline Scores & 5 & 4 & 3 & 1
\end{tabular}

Three overall comforts of the three protective clothes have been evaluated by the five scale scores. Experiments conducted before certain preparation (this experiment test requirement for five minutes joint twist exercises such as hand, foot and neck, and then take five minutes rest). Subjects wore the three protective clothes doing the baseball pitching motion. Badminton smashes motion and the volleyball smash. All kinds of sports for five times, one minute rest was needed after each time, five minutes rest were needed after five times, took ten minutes rest when changed to each style, comfortable feelings were recorded just when subjects finished each motion (Tab 8 ).

Table 8. The table of subjective evaluation of comfort

\begin{tabular}{llll}
\hline & \multicolumn{2}{l}{ Comfortable feelings } \\
\cline { 2 - 4 } & Baseball & Badminton & Volleyball \\
\hline Style 1 & 3.3 & 2.9 & 3.3 \\
Style 2 & 3.3 & 3.3 & 3.2 \\
Style 3 & 3.9 & 3.7 & 3.9 \\
\hline
\end{tabular}

From the subjective evaluation, clothing comfort of style 1 is about 3. Style 2 is between $3-3.5$. Both of them showed a lower comfortableness. Style 3 subjective evaluation ranges between $3.5-4$, the subjects felt a better comfortableness. The above analysis shows that these three clothing not only has a certain function of protection in baseball. Badminton, and volleyball, but also has met the requirement of the human body.

\section{Discussion}

The direction and location of the applied force are obtained by biomechanical analysis of shoulder joint based on Newton's classical mechanics in this paper. The pressure range added to the muscle by the garment was gained by the constructing finite element simulation of the shoulder muscle. This model takes the comfortable pressure range as the boundary condition. The correct value of the model is supported by the change of the electromotive integral value during throwing motions. Through experimental verification analysis found that the product has a certain protective effect on the shoulder.

Considering the integrity of the clothing, this paper based on the investigational use of short-sleeved shirt production method of throwing sports protective clothing for the optimal design, so that it has a practical purpose. Developed a set of protective model to establish the experimental method. According to the study of this article, it also shows that the use of finite element simulation of the protection parameters have a certain practical feasibility, indicating that the use of the protective parameters of the production of clothing has a protective effect on the human body, it has a 
significance reference to other types of sports protective clothing research.

In the finite element simulation of the shoulder muscles protection, the muscles and tissues around the scapula were treated as the same material to analyze, Compared with the medical model of the shoulder muscle finite element model (Larrea, Farron \& Pioletti, 2011; Metan, Krishna \& Mohankumar, 2014; Park \& An, 2001), the accuracy of this model is not high. But for clothing protection and comfort research, it has been in a position to meet the requirements. In this paper, the finite element model is utilized to find the optimal protective pressure value and pressure area, which greatly reduces the workload of the actual experiment. And the results confirmed by experiment with the actual experimental results are consistent. Thus in the throwing movement, the shoulder pressure added by the protective tape helps protect the shoulder from movement damage (Zanella, Willey \& Seibel, 2001; Lin, Hung \&Yang, 2011; Suhn, Duck \& Taek , 2008), and the size of the protective effect is related to both the material of the tape and the width of the protective tape (Kim \& Park, 2015).

Since this article has just studied the protect function in the throwing motions including the baseball pitching, the badminton smash, the process of volleyball smash, and the javelin throwing process, whether the protective clothes will have a effluence to the other motions in those throwing sports is not clear, so the whole throwing sports progress should be considered in the latter study. Only the mechanism of the shoulder in throwing sports has been studied. The thermal and moisture performance of the fabrics has not been discussed detestably.

\section{Conclusions}

The biomechanics principles of muscle were analyzed based on Newton's classical mechanics. A finite element analysis was used to simulate the shoulder muscles protection, in this shoulder muscle protection model, the stress contour and the highest stress value of the muscle with different protective area $\left(0 \mathrm{~cm}^{2}, 1 \mathrm{~cm}^{2}, 4 \mathrm{~cm}^{2}, 9 \mathrm{~cm}^{2}, 16 \mathrm{~cm}^{2}\right)$ has been simulated. $16 \mathrm{~cm}^{2}$ was selected as the most appropriate protective area. By this way, protective parameters were got to make the protective clothes. And then 3 styles protective clothes have been made according to the protective parameters. Finally, protective performance and the comfortableness have been evaluated by ten healthy participants using the IEMG and the five subjective feeling scale scores. The throwing test including the baseball pitching, the badminton smash, the process of volleyball smash, and the javelin throwing process. Three protective clothing styles have been produced and all of them have protecting effect to the muscle while participants doing the baseball pitching motion. Badminton smashes motion and the volleyball smash. And also have met the requirement of the human body. But protecting effect each style given was different in different sports motions.

There are two aspects can be further studied:

This paper focuses on the study of shoulder muscle protection in the upper extremity, and the focus of shoulder muscle protection is the study on the muscle protection in the shoulder muscle group. Therefore, the focus of future research can be gradually extended to the protective research of other human tissues involved in the movement.

The finite element analysis method is applied to see the mechanical properties of muscle tissue under comfortable pressure. The statistical data has some reference value for the study of the pressure comfort of the lower extremity of the body and the design of the fabric structure and elastic force of the garter.

In the process of finite element modeling, the finite element model is a simplified model of shoulder musculoskeletal model.The structure of human body is more complex, the outer surface of human body is concave and convex, the human body contains various other organization structure, these organization structure is cooperate with each other.Therefore, the complexity of the finite element model needs to be expanded, including the number of human tissues, the size of three-dimensional space and the shape of the human simulation model.

\section{References}

An, X. J. (2015). M. E. Biomechanics modeling and finite element simulation of human muscle, Harbin University of Science and Technology, Harbin. http://d.g.wanfangdata.com.cn/Thesis_Y1802347.aspx

Beckett M, Hannon M, Ropiak C, et al. (2014). Clinical assessment of scapula and hip joint function in preadolescent and adolescent baseball players. American Journal of Sports Medicine, 42(10), 2502-2509. https://doi.org/10.1177/0363546514542804

Büchler P, Ramaniraka N A, Rakotomanana L R, et al. (2002). A finite element model of the shoulder: application to the comparison of normal and osteoarthritic joints. Clinical Biomechanics, 17(9-10), 630-639. https://doi.org/10.1016/S0268-0033(02)00106-7

Fridén, J., R. L. Lieber. (1992). Structural and mechanical basis of exercise-induced muscle injury. Medicine \& Science in Sports \& Exercise, 24(5), 521-530. https://doi.org/10.1249/00005768-199205000-00005 
Fritz R C, Stoller D W. (1997). MR imaging of the rotator cuff. Magnetic Resonance Imaging Clinics of North America, $5(4)$,

735. http://xueshu.baidu.com/s?wd=paperuri:(70bad7bc5b2fd2b4fd6e2ec6ef17ce71)\&filter=sc_long_sign\&sc_ks_pa $\mathrm{ra}=\mathrm{q} \% 3 \mathrm{DMR}+$ imaging + of + the + rotator+cuff $\& \mathrm{tn}=$ SE_baiduxueshu_c1gjeupa $\&$ ie $=u t f-8 \&$ sc_us $=1618344837055$ 5852925

Gao, X. X. (2014). M. E. The biomechanics modeling and simulation of human muscle based on finite element. Harbin university of science and technology, Harbin. http://d.g.wanfangdata.com.cn/Thesis_Y2509226.aspx

Gowan I D, Jobe F W, Tibone J E, et al. (1987). A comparative electromyographic analysis of the shoulder during pitching. Professional versus amateur pitchers. Am J Sports Med, 15(6), 586-590. https://doi.org/10.1177/036354658701500611

Inman V T, Saunders J B, Abbott L C. (1996). Observations of the function of the shoulder joint. 1944. Clinical Orthopaedics \& Related Research, 330(330), 3. https://doi.org/10.1097/00003086-199609000-00002

Jian W. (2000). Some advances in the research of sEMG signal analysis and its application. 56-60, Sports Sci. 20(4). http://xueshu.baidu.com/s?wd=paperuri:(09b2c12644fef4aac5dc5bf382f2a2c7)\&filter=sc_long_sign\&sc_ks_pa $\mathrm{ra}=\mathrm{q} \% 3 \mathrm{DSome}+$ Advances $+\mathrm{in}+$ the + Research + of + sEMG + Signal + Analysis + and + Its + Application\&tn=SE_baidu xueshu_c1gjeupa\&ie=utf-8\&sc_us=3238155934111357535

Jobe F W, Tibone J E, Perry J, et al. (1983). An EMG analysis of the shoulder in throwing and pitching. A preliminary report. American Journal of Sports Medicine, $11(1), 3$. https://doi.org/10.1177/036354658301100102

Kim J S, Park M C. (2015). Changes of Shoulder Muscles Activity during Maintaining and Lifting Shoulder Depending on Stretch Rate of Kinesio Tape. 27(5), 299-303. http://xueshu.baidu.com/s?wd=Changes+of+Shoulder+Muscles+Activity+during+Maintaining+and+Lifting+Sh oulder+Depending+on+Stretch+Rate+of+Kinesio+Tape \&tn=SE_baiduxueshu_c1gjeupa\&cl=3\&ie=utf-8\&bs=T he+effects+of+scapular+taping+on+electromyographic+muscle+activity+and+proprioception+feedback+in+hea 1thy+shoulders\&f=8\&rsv_bp=1\&rsv_sug2=1\&sc_f_para=sc_tasktype\%3D\%7BfirstSimpleSearch\%7D

Knudson D. (2012). Mechanics of the Musculoskeletal System. Wolters Kluwer Health/Lippincott Williams \& Wilkins, 223-225 P.

Lädermann, A., Chagué, S., Kolo F C, et al. (2014). Kinematics of the shoulder joint in tennis players. Journal of Science \& Medicine in Sport, $19(1), \quad$ 56-63. http://xueshu.baidu.com/s?wd=paperuri:(9ca9fc0cec37e01afaee50589a4327e5)\&filter=sc_long_sign\&sc_ks_pa $\mathrm{ra}=\mathrm{q} \% 3 \mathrm{DKinematics}+\mathrm{of}+$ the + shoulder+joint+in+tennis+players\&tn=SE_baiduxueshu_c1gjeupa\&ie=utf-8\&sc_ us $=7757995396271397497$

Larrea, X., Farron, A., Pioletti, D., et al. (2011). Shoulder muscle forces during abduction with subscapularis deficiency after total shoulder arthroplasty. Computer Methods in Biomechanics \& Biomedical Engineering, 14(sup1), 19-20. https://doi.org/10.1080/10255842.2011.591527

Lin J J, Hung C J, Yang P L. (2011). The effects of scapular taping on electromyographic muscle activity and proprioception feedback in healthy shoulders. Journal of Orthopaedic Research Official Publication of the Orthopaedic Research Society, 29(1), 53. https://doi.org/10.1002/jor.21146

Meng lihua. (2015). Investigation and analysis of athletic injury of a college baseball team. Capital Institute Of Physical

Education. http://kns.cnki.net/KCMS/detail/detail.aspx?dbcode=CMFD\&dbname=CMFD201502\&filename $=1015567246$. nh\&uid=WEEvREcwSIJHSldRa1Fhb09jMjVzYjk2UllEZnpCbkFHbVBMcjFZa2tzYz0=\$9A4hF_YAuvQ5obg VAqNKPCYcEjKensW4ggI8Fm4gTkoUKaID8j8gFw!!\&v=MjYwNjNMdXhZUzdEaDFUM3FUcldNMUZyQ 1VSTDJlWitkbkZDdmtVci9CVkYyNkc3YStHZFBJcVpFYlBJUjhlWDE=

Metan S S, Krishna P, Mohankumar G C. (2014). FEM Model an Effective Tool to Evaluate Von Mises Stresses in Shoulder Joint and Muscles for Adduction and Abduction. Procedia Materials Science, 5, 2090-2098. https://doi.org/10.1016/j.mspro.2014.07.544

Nie, W. Z., Ye, M., Wang, C. T. (2010). Research on muscle force prediction of human banding based on quadric programming method, 29(2), 143-148. http://kns.cnki.net/KCMS/detail/detail.aspx?dbcode=CJFQ\&dbname=CJFDLAST2015\&filename=BJSC20100 2011\&uid=WEEvREcwSIJHSldRa1Fhb09jMjVzYjk2UllEZnpCbkFHbVBMcjFZa2tzYz0=\$9A4hF_YAuvQ5o 
bgVAqNKPCYcEjKensW4ggI8Fm4gTkoUKaID8j8gFw!!\&v=MTM1NzVFW11SOGVYMUx1eFITNORoMVQ zcVRyV00xRnJDVVJMMmVaK2RuRkN2bFViekFKeWZZYmJHNEg5SE1yWTk=

Nordin, M. V. H. Frankel. (2001). Basic Biomechanics of the Musculoskeletal System. 3rd ed., pp. 155-161, LWW, New York. http://book.kongfz.com/99753/189776143/

Park J S. (2016). An Application Effect Analysis of Mulligan Taping on Neck and Shoulder During Computer Typing Works -Focused on Muscle Activity and Muscle Fatigue. 10(1), 79. http://xueshu.baidu.com/s?wd=paperuri:(da415a107dc16c3e82cf72121ee71350)\&filter=sc_long_sign\&sc_ks_p ara $=q \% 3 \mathrm{DAn}+$ Application+Effect+Analysis+of+Mulligan+Taping+on+Neck+and+Shoulder+During+Compute $\mathrm{r}+$ Typing+Works+-Focused+on+Muscle+Activity+and+Muscle+Fatigue-\&tn=SE_baiduxueshu_c1gjeupa\&ie=u tf-8\&sc_us=17869689892688908402

Wang, S. K. (2016). M. E. Research on running protective sports trousers based on biomechanics, SUES, Shanghai. http://d.g.wanfangdata.com.cn/Thesis_D688984.aspx

Wang, S. K. (2016). M. E. Research on running protective sports trousers based on biomechanics, SUES, Shanghai. http://d.g.wanfangdata.com.cn/Thesis_D688984.aspx

Yuan, G. X., W. B. Zhang. (2011). Finite element analysis in the musculoskeletal system model applied in the study of material properties. International Journal of Orthopaedics, 32(6), 352-355. http://kns.cnki.net/KCMS/detail/detail.aspx?dbcode=CJFQ\&dbname=CJFD2011\&filename=GWGK201106005 \&uid=WEEvREcwSIJHSldRa1Fhb09jMjVzYjk2UllEZnpCbkFHbVBMcjFZa2tzYz0=\$9A4hF_YAuvQ5obgVA qNKPCYcEjKensW4ggI8Fm4gTkoUKaID8j8gFw!!\&v=MDkzNDJDVVJMMmVaK2RuRkN2a1dyM0JJanJN WmJHNEg5RE1xWTIGWVISOGVYMUx1eFITNORoMVQzcVRyV00xRnI=

Zanella P W, Willey S M, Seibel S L, et al. (2001). The Effect of Scapular Taping on Shoulder Joint Repositioning. Journal of Sport Rehabilitation, 10(2), 113-123. https://doi.org/10.1123/jsr.10.2.113 